\title{
CHEMBIOCHEM
}

DOI: 10.1002/cbic.201000545

\section{Structure and Function of Histone H3 Lysine 9 Methyltransferases and Demethylases}

Swathi Krishnan, ${ }^{[a]}$ Scott Horowitz, ${ }^{[b]}$ and Raymond C. Trievel ${ }^{*[c]}$

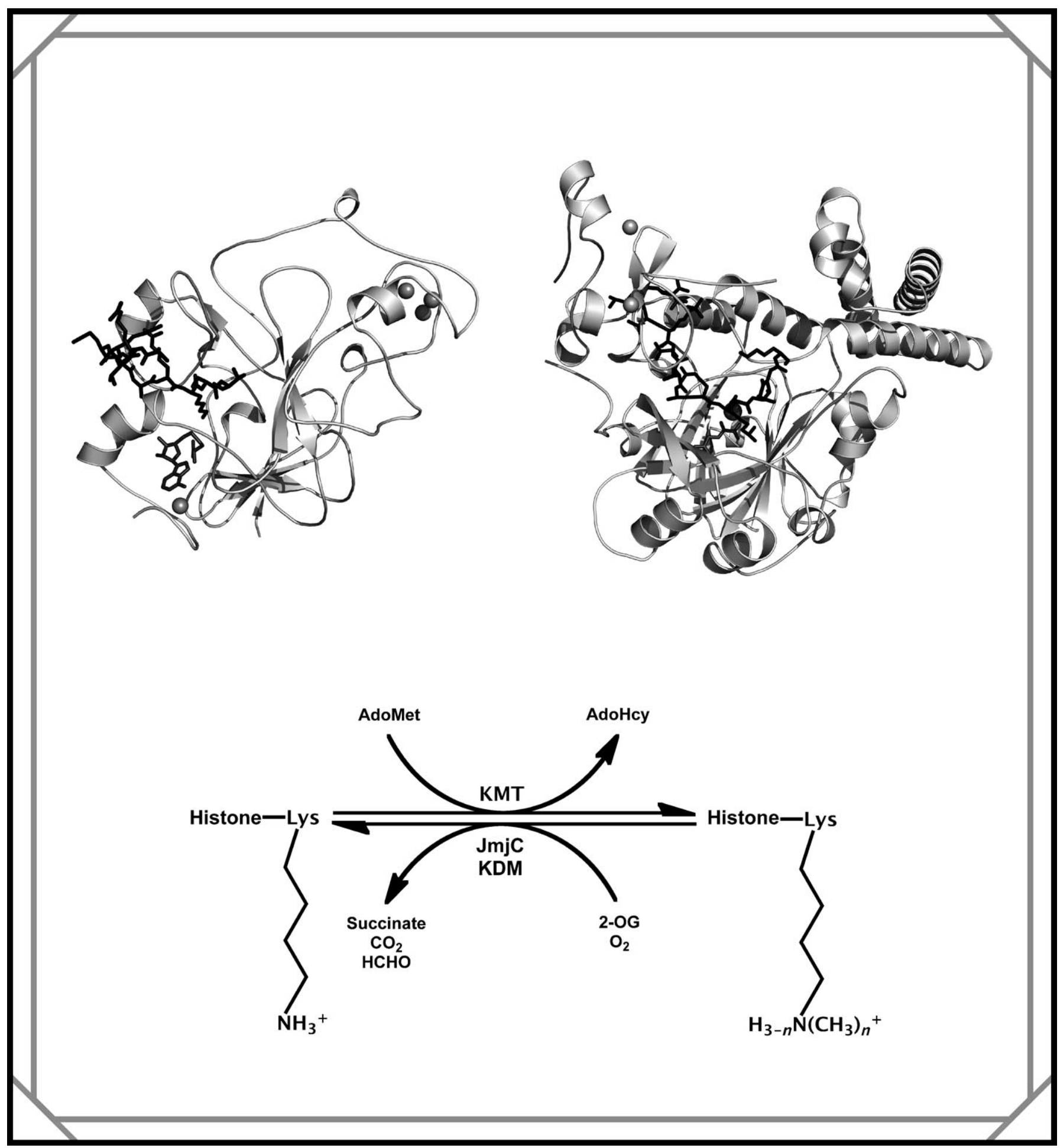


Histone lysine methylation is a dynamic chromatin modification that plays key regulatory roles in gene expression and other genomic functions. Methylation of Lys9 in histone $\mathrm{H} 3$ (H3K9) is a prominent modification that has been implicated in diverse processes, including transcriptional silencing, heterochromatin formation, and DNA methylation. In this review, we summarize recent advances in understanding the structure and substrate specificity of the H3K9-specific methyltransferas- es G9A and GLP and explore current efforts to develop inhibitors of these enzymes. In addition, we discuss the structure and specificity of the recently discovered PHF8 family of histone demethylases that target $\mathrm{H} 3 \mathrm{~K} 9$ as well as other methylation sites in histones $\mathrm{H} 3$ and H4. Finally, we conclude by comparing the H3K9 binding modes displayed by these enzymes and examine the relevance of these studies to their biological functions and to structure-based inhibitor design.

\section{Introduction}

Eukaryotic DNA is packaged into a nucleoprotein complex termed chromatin. The fundamental repeating unit of chromatin is the nucleosome core particle, which is composed of $\sim 150$ base pairs of DNA wound around an octameric core of two molecules each of the core histones $\mathrm{H} 2 \mathrm{~A}, \mathrm{H} 2 \mathrm{~B}, \mathrm{H} 3$, and $\mathrm{H} 4 .^{[1]}$ Nucleosome core particles can be arranged into a compact hierarchical architecture, yielding a repressive environment that inhibits transcription and other processes that require access to the DNA template. Post-translational modification of histones represents one mechanism by which chromatin structure is modulated to alter DNA accessibility. Post-translational modifications include acetylation, methylation, phosphorylation, ubiquitination, and sumoylation. ${ }^{[2]}$ These modifications can function individually or combinatorially to elicit specific effects based on changes in chromatin structure or the recruitment of effector proteins that recognize specific patterns of histone marks. ${ }^{[2-3]}$ Histone lysine methylation has gained prominence due to its central role in transcriptional regulation and in other genomic functions. Lysine methylation predominantly occurs in histones $\mathrm{H} 3$ and $\mathrm{H} 4$ and elicits specific effects depending on the site and degree of methylation. For example, methylation of $\mathrm{H} 3 \mathrm{~K} 4, \mathrm{H} 3 \mathrm{~K} 36$, and $\mathrm{H} 3 \mathrm{~K} 79$ is generally associated with actively transcribed genes, whereas H3K9, $\mathrm{H} 3 \mathrm{~K} 27$, and H4K20 methylation frequently demarcate silent chromatin. ${ }^{[4]}$ Furthermore, the lysine $\varepsilon$-amine group can be mono-, di-, or trimethylated, thus imparting an additional hierarchy in methyllysine-mediated signaling. The effects ascribed to histone lysine methylation are frequently mediated by effector proteins possessing methyllysine binding domains that can differentiate among different sites and degrees of lysine methylation..$^{[5]}$

Methylation of H3K9 has emerged as an important modification that is associated with transcriptional silencing, heterochromatin formation, and DNA methylation. Studies in organisms ranging from fission yeast to humans have shown that H3K9 methylation is a hallmark of facultative and constitutive heterochromatin. ${ }^{[6]}$ However, high-resolution mapping of histone modification patterns in human $\mathrm{CD}^{+}$cells have shown that di- and trimethylation of Lys9 (H3K9me2 and H3K9me3) are enriched in the transcriptional start sites of silenced genes, whereas $\mathrm{H} 3 \mathrm{~K} 9 \mathrm{me} 1$ is present in the promoter regions of active genes. ${ }^{[7]}$ These findings suggest that the methylation state of H3K9 might be an important marker denoting transcriptional status of a given gene. In the context of heterochromatin, methylation of $\mathrm{H} 3 \mathrm{~K} 9$ has been implicated in the early stages of $\mathrm{X}$-chromosome inactivation, ${ }^{[8]}$ whereas $\mathrm{H} 3 \mathrm{~K} 9 \mathrm{me} 3$ is associated with pericentric heterochromatin. ${ }^{[9]}$ In addition, H3K9 methylation has been linked to DNA methylation in CpG sequences through coordination of the enzymatic complexes that catalyze methylation at H3K9 and CpG repeats (reviewed by Cheng and Blumenthal $\left.{ }^{[10]}\right)$. In summary, these findings highlight the importance of $\mathrm{H} 3 \mathrm{~K} 9$ methylation in heterochromatin structure and transcriptional regulation.

The methylation status of $\mathrm{H} 3 \mathrm{~K} 9$ is subject to dynamic regulation through the concerted activities of lysine methyltransferases (KMTs) and lysine demethylases (KDMs). Within the last decade, studies in numerous organisms have identified a multitude of H3K9-specific KMTs that belong to the SET domain family. ${ }^{[11]}$ The mammalian homologues of these enzymes include G9A (KMT1C) $)^{[12]}$ and its homologue G9A-like protein (GLP; KMT1D), ${ }^{[13]}$ SETDB1 (KMT1E), ${ }^{[14]}$ PRDM2 (also known as $\mathrm{RIZ1}$ and KMT8), ${ }^{[15]}$ and SUV39H1 and its homologue SUV39H2 (KMT1A and KMT1B). ${ }^{[16]}$ Following the discovery of these KMTs, several H3K9-specific KDMs belonging to the Jumonji C (JmjC) class of KDMs were isolated and characterized, including the JHDM2 (KDM3), ${ }^{[17]}$ JMJD2 (KDM4), ${ }^{[18]}$ and PHF8 (KDM7) families. ${ }^{[19]}$ Here, we review the recently reported structures of G9A and GLP KMTs and the PHF8 KDM in complex with histone $\mathrm{H} 3$ peptides as well as the structures of GLP and G9A bound to small-molecule inhibitors. These structures provide a framework defining the molecular specificity of these enzymes for H3K9 and furnish insight into the mechanisms by which small molecules selectively inhibit the G9A family of KMTs. Finally, we summarize the broader implications of these studies for our understanding of the enzymology of histone methylation

\footnotetext{
[a] S. Krishnan ${ }^{+}$

University of Michigan Medical School, Department of Biological Chemistry 1150 West Medical Center Drive, 4315 Medical Science Research Building III Ann Arbor, MI 48109 (USA)

[b] S. Horowitz ${ }^{+}$

University of Michigan, Biophysics Graduate Program Ann Arbor, MI 48109 (USA)

[c] Prof. R. C. Trievel

University of Michigan Medical School, Department of Biological Chemistry 1150 West Medical Center Drive, 5301 Medical Science Research Building III Ann Arbor, MI 48109 (USA)

Fax: $(+1) 734-763-4581$

E-mail:rtrievel@umich.edu

$\left.{ }^{+}\right]$These authors contributed equally to this work.
} 
and its biological functions, and discuss current efforts to develop structure-based inhibitors of KMTs and KDMs.

\section{H3K9 methylation by G9A and GLP}

The importance of histone methylation to gene regulation and human health has been widely acknowledged. ${ }^{[3,20]}$ The majority

\begin{abstract}
Raymond Trievel received his Ph.D. in biochemistry and biophysics from the University of Pennsylvania in 2000. After doctoral studies in the laboratory of Dr. Ronen Marmorstein (Wistar Institute), where he characterized the structure, mechanism, and substrate specificity of the GCN5 family of histone acetyltransferases, R.T. became a postdoctoral fellow in the laboratory of Dr. James Hurley (National Institutes of Health), where he determined one

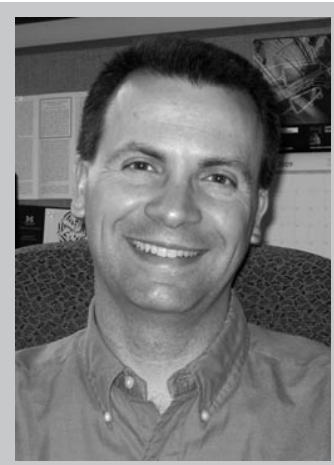
of the first structures of a SET-domain lysine methyltransferase. In 2003, R.T. joined the Department of Biological Chemistry at the University of Michigan, becoming an associate professor in 2009. His current research focuses on the structure, catalytic mechanisms, and substrate specificity of lysine methyltransferases and demethylases.
\end{abstract}

Swathi Krishnan is a graduate student in the Department of Biological Chemistry at the University of Michigan, Ann Arbor. She received her Bachelor's Degree in biotechnology from PSG College of Technology, India in 2007. After a one-year stint at the National Center for Biological Sciences, India, she came to Michigan through the Program in Biomedical Sciences. Her current research in the Trievel Lab entails understanding the structure and specificity of the Jumonji C family of lysine demethylases.

Scott Horowitz is currently a Ph.D. candidate at the University of Michigan. He obtained his B.A. in molecular biology and biochemistry and his M.A. in chemistry from Wesleyan University. Afterwards, he began his doctoral studies as part of the University of Michigan Biophysics Department, investigating carbon-oxygen $(\mathrm{CH} \cdots \mathrm{O})$ hydrogen bonds in biological methyltransfer reactions. His current work focuses on developing new techniques

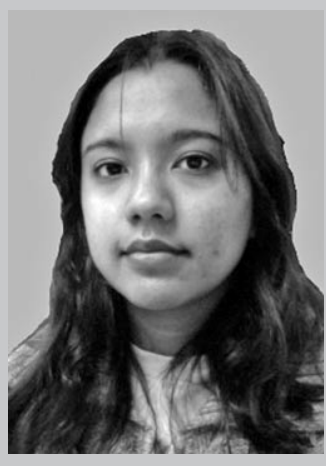

to identify $\mathrm{CH}$...O hydrogen bonds within bio-macromolecules and to evaluate the structural, dynamic, and functional effects of these interactions in biology. of histone methylation reactions are catalyzed by SET-domain KMTs, a family of S-adenosylmethionine (AdoMet)-dependent enzymes that encompasses over 50 proteins in humans. ${ }^{[21]}$ Two H3K9-specific KMTs, G9A and GLP, have been found to be important in many biological processes that are associated with gene regulation. In euchromatin, G9A and GLP silence gene expression through $\mathrm{H} 3 \mathrm{~K} 9$ methylation, and deletion of either KMT is lethal to mouse embryos. ${ }^{[22]}$ In addition, G9A plays a critical role in regulating embryonic stem cell (ESC) differentiation through silencing the gene that encodes the pluripotency-determining transcription factor Oct $3 / 4,{ }^{[23]}$ although it can be partially restored through shRNA-mediated knockdown of G9A. ${ }^{[24]}$ Furthermore, a point mutation in the catalytic domain of G9A was shown to prevent heterochromatin formation at the Oct3/4 gene in ESCs, thereby confirming the importance of its methyltransferase activity in the repression of ESC pluripotency. ${ }^{[25]}$ Beyond its role in regulating ESC differentiation, G9A has been implicated in DNA CpG methylation of silenced genes. ${ }^{[26]}$ Specifically, the ankyrin repeat domain of G9A has been shown to physically recruit DNA methyltransferases DNMT3A and DNMT3B to silenced loci, a function that appears to be independent of its $\mathrm{H} 3 \mathrm{~K} 9$ methyltransferase activity. ${ }^{[25]}$ For a comprehensive review of the roles of G9A and GLP in DNA methylation, see Cheng and Blumenthal. ${ }^{[10]}$

In addition to their functions in gene regulation and cellular differentiation, H3K9 KMTs have been implicated in many cancers. For example, G9A and SUV39H1 were found to be important in perpetuating malignancy in cancer cells. ${ }^{[27]}$ Specifically, H3K9 dimethylation by G9A has been linked to aberrant silencing of tumor-suppressor genes, thereby promoting unchecked cell proliferation. ${ }^{[28]}$ Furthermore, G9A and GLP can methylate Lys373 within the regulatory domain of transcription factor p53, inhibiting its tumor-suppressor activity. ${ }^{[29]}$ Taken together, these findings highlight the oncogenic potential of H3K9 KMTs, rendering these enzymes attractive targets for the design of novel chemotherapeutic drugs.

\section{Structural basis for H3K9 recognition by G9A and GLP}

Structural studies over the last several years have elucidated the structure, specificity, and mechanism of several SET-domain KMTs. ${ }^{[11,30]}$ These enzymes possess a conserved catalytic SET domain flanked by $\mathrm{N}$ - and $\mathrm{C}$-terminal domains that vary in size and tertiary structure. The SET domain adopts a pseudo-knottype structure consisting of a $\beta$-sheet fold bifurcated by an $\alpha$ helical iSET motif. ${ }^{[11 a, 31]}$ The SET domain contains a central channel that accommodates the binding of AdoMet and the protein substrate on opposite faces of the domain. AdoMet binds and positions its methyl group at the base of the channel. At the other end, the protein substrate binds in extended conformation, with the side chain of the target lysine protruding into the channel. Hydrogen bonding to the substrates within the channel positions the AdoMet methyl group and the lysine $\varepsilon$-amine for methyl transfer through an $S_{N} 2$ reaction. ${ }^{[32]}$ With respect to their site specificity, numerous structural studies have provided key insights into substrate recognition by various SET-domain KMTs, including DIM-5, ${ }^{[32 c]} \mathrm{SET} 7 / 9$ 
(KMT7), ${ }^{[32 b, 33]}$ SET8 (also known as PR-SET7 and KMT5A), ${ }^{[34]}$ MLL1 (KMT2A), ${ }^{[35]}$ and vSET. ${ }^{[36]}$ Recently, several crystal structures of G9A and GLP in complex with a histone $\mathrm{H} 3$ peptide and small-molecule inhibitors have been reported, ${ }^{[37]}$ thereby greatly expanding our knowledge of the mechanisms by which H3K9 KMTs recognize their target and how this recognition can be co-opted for inhibitor design. ${ }^{[38]}$

Wu et al. have determined the crystal structures of several H3K9-specific KMTs, including G9A, GLP, SUV39H2, and PRDM2. ${ }^{[37 e]}$ Of these structures, the ternary complexes of GLP (residues 951-1235) bound to the product S-adenosylhomocysteine (AdoHcy) and histone $\mathrm{H} 3$ peptide (residues 2-12) bearing $\mathrm{K} 9 \mathrm{me} 1$ and $\mathrm{K} 9 \mathrm{me} 2$ have offered the greatest insight into H3K9 specificity. In this review, we focus on the GLP complex with the H3K9me1 peptide (Figure $1 \mathrm{~A}$ ). The tertiary structure of the GLP catalytic domain is composed of the SET domain, which is flanked by an N-terminal PreSET domain and a C-terminal PostSET domain that features a $\mathrm{Zn}^{\text {"I-cysteine motif }}$ that closes around the substrates to complete the active site. Due to the high sequence and structural similarity of GLP and G9A, it is likely that many of the structural features discussed below for GLP are also relevant for G9A.

The structure of the GLP.AdoHcy-histone $\mathrm{H} 3$ peptide complex reveals the molecular details of H3K9 specificity through
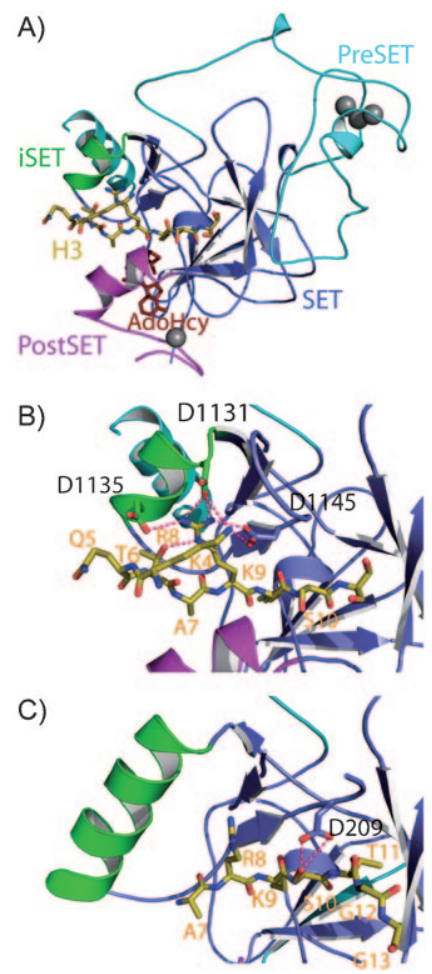

Figure 1. Structural basis of H3K9 recognition by GLP and DIM-5. A) Crystal structure of the catalytic domain of human GLP in complex with AdoHcy (red) and an H3K9me1 peptide (yellow carbon atoms; PDB ID: 3HNA). B) Substrate binding cleft of GLP bound to the H3K9me1 peptide (PDB ID: 3HNA). C) Substrate binding cleft of DIM-5 bound to a histone $\mathrm{H} 3$ peptide (PDB ID: 1PEG). Motifs of the catalytic domain are denoted in cyan (PreSET domain), blue (SET domain), green (iSET motif), and magenta (PostSET domain), zinc atoms are shown as gray spheres, and side-chain hydrogen bonds between H3K9me1 and GLP are depicted in pink. recognition of the residues flanking $\mathrm{K} 9$ in histone $\mathrm{H} 3 .^{[37 \mathrm{e}]}$ In the GLP ternary complex, the histone $\mathrm{H} 3$ peptide binds in extended conformation with several of its side chains engaging in hydrogen bonds to GLP (Figure 1B). Most of these interactions are mediated by the iSET domain, which serves as a docking platform for the histone $\mathrm{H} 3$ peptide, whereas some contacts with the substrate also occur to the PostSET domain. The structure of the GLP ternary complex clearly illustrates that the H3K9me1 side chain extends into the active site with its methyl group pointing toward the product AdoHcy. ${ }^{[37 e]}$ Previously, the only structural evidence for the substrate specificity of H3K9 KMTs was provided by the cocrystal structure of DIM5, a SUV39H1 homologue from Neurospora crassa, and a histone $\mathrm{H} 3$ peptide. ${ }^{[32 \mathrm{c}]}$ The structure of the DIM-5 complex reveals that $\mathrm{H} 3 \mathrm{~S} 10$ is a primary source of substrate recognition, due to hydrogen bonding between the S10 hydroxyl group and D209 in the enzyme (Figure 1C). This observation is consistent with substrate specificity studies on DIM-5, which demonstrated that $\mathrm{S} 10$ is important for H3K9 recognition. ${ }^{[39]}$ However, in the GLP ternary complex, H3S10 adopts an alternate conformation and forms hydrogen bonds to water molecules as opposed to the enzyme. ${ }^{[37 e]}$ Correlatively, substrate-specificity studies of G9A have demonstrated that the enzyme does not exhibit a strong preference for a serine residue in the +1 position of the methylation site. ${ }^{[40]}$ Thus, the capacity to recognize $\mathrm{S} 10$ represents one difference in the $\mathrm{H} 3 \mathrm{~K} 9$ recognition modes displayed by GLP and DIM-5.

Another key difference between the histone H3 peptide complexes of DIM-5 and GLP is their interaction with H3R8. In the GLP ternary complex, the side chain of R8 forms multiple hydrogen bonds with the enzyme (Figure 1B); this is consistent with the fact that R8 mutations abolished H3K9 methylation by $\mathrm{GPA}^{[40]}$ However, in the structure of the DIM-5.AdoHcy-histone $\mathrm{H} 3$ peptide complex, R8 makes no hydrogen bonding contacts to DIM-5 (Figure 1C). ${ }^{[32]}$ Moreover, mutational analysis of R8 demonstrated that DIM-5 tolerates other residues in this position in histone $\mathrm{H} 3$, albeit with slightly diminished activity. ${ }^{[39]}$ The major conclusion to be drawn from these studies is that, although both G9A and DIM-5 recognize H3K9, their modes of recognition are quite dissimilar.

The effect of histone modifications on SET-domain KMT specificity is of particular interest due to the regulatory roles that the modifications of neighboring residues can have on lysine methylation. For example, biochemical studies have shown that phosphorylation of S10 and T11 (S10ph and T11ph) reduced the catalytic efficiency of G9A. ${ }^{[40-41]}$ In the GLP structures, S10 and T11 do not participate in direct interactions with the enzyme. It is conceivable that phosphorylation of these residues disrupts the electrostatic interactions that promote the binding of the basic N-terminal tail of histone $\mathrm{H} 3$ in the acidic substrate binding cleft of G9A and GLP. It is also worth noting that $\mathrm{R} 8$ can be methylated in vivo ${ }^{[42]}$ and that $\mathrm{R} 8$ methylation impairs methylation of H3K9 by G9A. ${ }^{[40]}$ These findings are in agreement with the structure of the ternary complex of GLP and illustrate that R8 recognition is critical for H3K9 methylation. ${ }^{[37 e]}$ 
Another interesting point regarding the effect of histone $\mathrm{H} 3$ post-translational modifications on G9A and GLP specificity concerns the hydrogen bonding between the $\varepsilon$-amine from the side chain of H3K4 and the carboxylate groups of D1131 and D1145 in GLP (Figure 1 B). Wu et al. proposed that methylated forms of $\mathrm{H} 3 \mathrm{~K} 4$ would be unable to bind in the same groove, thereby reducing the binding affinity and turnover number of the enzyme. ${ }^{[37]}$ However, when they tested this hypothesis, they found that the affinity for an $\mathrm{H} 3 \mathrm{~K} 4 \mathrm{me} 3$ peptide was modestly decreased, and $k_{\text {cat }}$ was unaltered in comparison to the unmodified $\mathrm{H} 3$ peptide. Further, H3K4me1 and H3K4me2 had no significant effect on either substrate binding or the turnover number. These data are in agreement with prior studies demonstrating that G9A exhibited a modest decrease in catalytic efficiency when assayed with an H3K4me3 peptide in comparison to an unmodified $\mathrm{H} 3$ peptide substrate. ${ }^{[41]}$ It is conceivable that the H3K4 binding site in GLP is a product of crystallization with a short peptide construct that does not fully recapitulate the binding mode of a nucleosomal substrate. Alternatively, the similarity in the catalytic efficiency for the methylation of the H3K4me1, H3K4me2, and unmodified $\mathrm{H} 3$ peptides could be due to the ability of methylated $\mathrm{K} 4$ to form carbon-oxygen $(\mathrm{CH} \cdots \mathrm{O})$ hydrogen bonds with the side chains of D1131 and D1145, as was previously reported for methyllysine binding in the active sites of SET-domain KMTs. ${ }^{[32 a, 43]}$ Future structural and functional investigations will aid in further elucidating the impact post-translational modifications of the residues in the N-terminal tail of histone $\mathrm{H} 3$ have on substrate recognition by G9A and GLP.

\section{Small-molecule inhibitors of G9A and GLP}

The availability of H3K9 KMT structures has provided an opportunity to develop inhibitors through structure-based design. The catalytic domains of KMTs offer two potential targets for inhibition: 1) the AdoMet cofactor binding site and 2) the protein substrate binding cleft. Certain natural products have been shown to act as competitive inhibitors of AdoMet, including sinefungin, chaetocin, and the product cofactor AdoHcy. Sinefungin and AdoHcy are structurally related to AdoMet and are not KMT-specific, ${ }^{[43 b, 44]}$ whereas chaetocin is a selective inhibitor of Drosophila SU(VAR)3-9, a homologue of human SUV39H $1 .{ }^{[45]}$ The second category comprises inhibitors that bind within the protein substrate binding cleft of the KMT. Among the first of these to be discovered was the small molecule BIX-01294, which was identified as a specific inhibitor of G9A and GLP. BIX-01294 reduced H3K9me2 levels in cells ${ }^{[46]}$ and was later shown to promote stem-cell reprogramming, comparable to the activity associated with viral transduction of pluripotency-inducing transcription factors. ${ }^{[47]}$

To understand the structural basis for inhibition by BIX01294, Chang et al. determined its structure in complex with GLP. ${ }^{[37 b]}$ The inhibitor binds in the substrate binding cleft of GLP by forming many hydrogen bonds and van der Waals contacts comparable to those observed in the histone $\mathrm{H} 3$ peptide complex (Figure 2A, B). The quinazoline ring of BIX-01294 binds in a region analogous to that occupied by the backbone
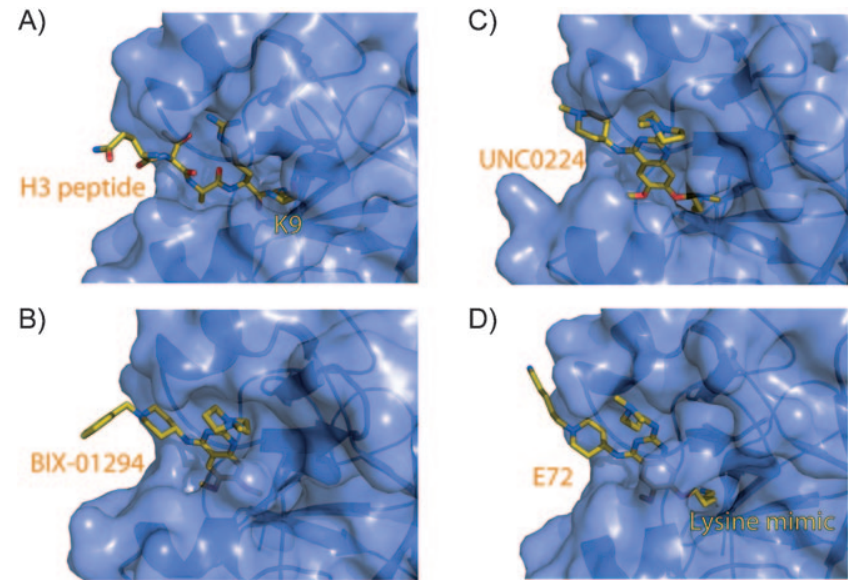

D)

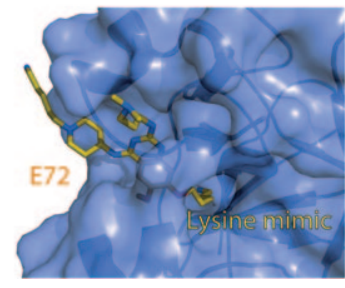

Figure 2. Small-molecule inhibitors of G9A and GLP that mimic an H3K9 peptide. In each panel, the substrate binding cleft of human GLP or G9A (purple) is rendered with both secondary structure and surface shown, while bound ligands (yellow carbons) are represented in stick form. A) H3K9me1 peptide in complex with GLP (PDB ID: 3HNA). B) BIX-01294 in complex with GLP (PDB ID: 3FPD). C) UNC0224 bound to G9A (PDB ID: 3K5K). D) E72 bound to GLP (PDB ID: 3MO5).

atoms of residues T6-R8 in the histone $\mathrm{H} 3$ peptide as well as the side chain of R8. It is not surprising that BIX-01294 closely mimics the conformation of R8, as this residue has been shown to be critical for G9A activity. ${ }^{[40]}$ Further similarities between the inhibitor and substrate binding modes include the diazepane ring of BIX-01294, which inhabits roughly the same binding pocket as the side chain of $\mathrm{K} 4$, and the benzene and piperidine groups, which occupy the approximate positions of residues Q5 and T6, respectively. To enhance its binding affinity, Liu et al. derivatized the quinazoline scaffold of BIX-01294 to obtain a new inhibitor, UNC0224, which bound to G9A with a $K_{\mathrm{D}}$ value of $23 \mathrm{~nm}$, an approximately fivefold higher affinity than that measured for BIX-01294 $\left(K_{D}=130 \mathrm{~nm}\right)^{[37 \mathrm{c}]}$ (Figure 2C). Further optimization of UNC0224 yielded a new analogue that displayed picomolar inhibition of G9A. ${ }^{[37 d]}$ Very recently, a derivative of BIX-01294 was designed with unmodified and methylated lysine mimics appended to the quinazoline that extend into the enzyme's lysine binding channel, thus yielding an inhibitor seven times more potent (E72; Figure 2D). ${ }^{[37 a]}$ Collectively, these studies illustrate the feasibility of structurebased design and optimization of inhibitors that target the substrate binding cleft of H3K9 KMTs and provide a blueprint for developing inhibitors of other SET-domain enzymes. In the future, this approach might allow peptide-mimic drug design for other oncogenic SET-domain KMTs, such as $\mathrm{EZH}^{2[8]}$ and SMYD3. ${ }^{[49]}$

\section{PHF8 Family of KDMs}

Plant homeodomain finger protein 8 (PHF8) and its homologues represent one of the most recently discovered families of KDMs. These enzymes are members of the JmjC class of KDMs, which are mononuclear $\mathrm{Fe}^{\text {Il-dependent hydroxylases }}$ that catalyze demethylation through an oxidative mechanism by using the cosubstrates 2-oxoglutarate (2-OG) and $\mathrm{O}_{2}$. In 
humans, there are three members of the PHF8 family: the founding member PHF8, a related homologue KIAA1718, ${ }^{[50]}$ and PHF2, a homologue that shares sequence homology with PHF8 and KIAA1718; however, its JmjC domain harbors a mutation in one of the Fe"-coordinating residues and is predicted to lack demethylase activity. ${ }^{[50]}$ PHF8 homologues have also been characterized in other metazoans, including C. elegans and zebrafish. ${ }^{[51]}$ Sequence analysis reveals that these homologues share a conserved domain architecture consisting of an $\mathrm{N}$-terminal plant homeodomain (PHD), which can bind H3K4me3 (see below), followed by the JmjC catalytic domain. The PHF8 KDMs display a relatively broad specificity in demethylating the mono- and dimethylated states of $\mathrm{H} 3 \mathrm{~K} 9, \mathrm{H} 3 \mathrm{~K} 27$, and $\mathrm{H} 3 \mathrm{~K}_{3} 6^{[19 \mathrm{~b}]}$ although PHF8 has been reported to prefer mono- and dimethyl H3K9 (H3K9me1/2) in a peptide-bearing H3K4me3. ${ }^{[19 a]}$ Surprisingly, two independent studies by Liu et al. and Qi et al. have recently reported that PHF8 can also demethylate H4K20me1 in the context of nucleosomal substrates, ${ }^{[52]}$ this suggests that the specificity of the PHF8 family is broader than initially reported. ${ }^{[19 b]}$ In this review, we focus on human PHF8 due to its relationship to X-linked mental retardation (XLMR) as well as the recently published crystal structure of the enzyme in complex with a doubly methylated H3K4me3K9me2 peptide, which offers insight into substrate binding and catalysis.

Prior to its identification as a KDM, mutations or deletions in the PHF8 gene were shown to be associated with Siderius XLMR syndrome, a condition characterized by mild mental retardation, a cleft lip and palate, and facial dysmorphism. ${ }^{[33]}$ Clinical mutations in PHF8 map to its JmjC catalytic domain; this suggests that the loss of its demethylase activity contributes to the onset of XLMR. Qiu et al. demonstrated that siRNAmediated knockdown of PHF8 in embryonic carcinoma cells impaired their ability to differentiate into a neuronal cell lineage when induced with retinoic acid. ${ }^{[54]}$ This effect could be rescued by transfecting with wild-type PHF8 but not the catalytically inactive F279S mutant associated with some XLMR patients. Correlatively, studies in zebrafish have shown that the PHF8 homologues KDM7a and KDM7b are essential for proper brain and craniofacial development, thus illustrating a conserved function for these KDMs in neuronal differentiation and morphological development in vertebrates. ${ }^{[51 \mathrm{~b}]}$

Recent studies have described multiple roles for PHF8 in transcriptional activation and in cell-cycle control. Zhu et al. and Feng et al. have reported that PHF8 localizes to the nucleoli, a major hub for rRNA transcription, where it associates with the rDNA promoter to coactivate the expression of rRNA genes. ${ }^{[55]}$ Furthermore, Feng et al. demonstrated that PHF8 physically associates with the RNA polymerase I transcriptional machinery and an $\mathrm{H} 3 \mathrm{~K} 4$ methyltransferase complex. ${ }^{[55 \mathrm{a}]}$ Association with the latter complex could be critical to PHF8 activity, as H3K4me3 binding to its chromodomain stimulated H3K9me2 demethylation by the enzyme. In a separate study, PHF8 was shown to interact with the C-terminal domain of RNA polymerase II directly and to mediate the coactivation of numerous genes through demethylation of $\mathrm{H} 3 \mathrm{~K} 9 \mathrm{me} 2{ }_{i}^{[56]}$ this is consistent with the recent finding that PHF8 associates with over 7000 genes in HeLa cells. ${ }^{[52 b]}$ With respect to XLMR, PHF8 was shown to associate with the ligand-bound form of retinoic acid receptor $\alpha$ and to coactivate the expression of genes involved in neuronal differentiation. ${ }^{[54]}$ Moreover, PHF8 binds to the XLMR-linked transcription factor ZNF711, which targets it to a subset of genes, including one that encodes JARID1C (KDM5C), a second KDM implicated in XLMR. ${ }^{[51 a]}$ Finally, Liu et al. have recently shown that PHF8 also participates in cellcycle control by demethylating H4K20me1 in the promoters of E2F1-inducible genes to promote progression through the G1$S$ phase transition. ${ }^{[52 a]}$ In early mitosis, PHF8 becomes phosphorylated and dissociates from chromatin, resulting in increased H4K20me1 and condensin II deposition that facilitates chromatin compaction. In summary, these studies illustrate diverse functions for PHF8 and underscore its importance as a transcriptional coactivator and a regulatory factor governing cell-cycle progression.

\section{Structure of PHF8 and recognition of H3K9me2}

Four independent groups have recently reported crystal structures of PHF8, KIAA1718, and the C. elegans homologue ceKDM7a. ${ }^{[19 a, 57]}$ Collectively, the structures reveal a conserved fold in which the $\mathrm{N}$-terminal PHD domain packs against the catalytic JmjC domain with an intervening linker of varying length bridging the two domains (Figure $3 \mathrm{~A}$ ). The JmjC domain of PHF8 adopts a $\beta$-barrel fold that is conserved in the structures of other JmjC KDMs, such as JMJD2A ${ }^{[58]}$ (Figure $3 \mathrm{~B}$ ). The Fe" and 2-OG binding sites are located within the center of the barrel, with the $\mathrm{Fe}^{\text {Il }}$ coordinated through a His-X-Glu... His motif that is conserved in JmjC enzymes.

Horton et al. investigated the substrate specificity of PHF8 by using a series of kinetic and binding assays. ${ }^{[19 a]}$ In agreement with prior studies of its specificity, ${ }^{[19 b]}$ they showed that PHF8 displayed weak demethylase activity toward a 24-residue H3K9me2 peptide substrate. In contrast, a histone H3 peptide incorporating both $\mathrm{K} 4 \mathrm{me} 3$ and $\mathrm{K} 9 \mathrm{me} 2$ (H3K4me3K9me2) was demethylated 70 times more efficiently than the identicallength $\mathrm{H} 3 \mathrm{~K} 9 \mathrm{me} 2$ peptide, based on the differences in the $k_{\mathrm{cat}}$ t $K_{\mathrm{M}}$ values for the respective substrates. Consistent with these findings, the doubly methylated H3K4me3K9me2 peptide bound to PHF8 with a $K_{\mathrm{D}}$ value of $1 \mu \mathrm{M}$, whereas the association of the $\mathrm{H} 3 \mathrm{~K} 9 \mathrm{me} 2$ peptide and the enzyme was too weak to be measured by calorimetry. These findings suggest that preferential binding of $\mathrm{H} 3 \mathrm{~K} 4 \mathrm{me} 3$ by PHF8 stimulates $\mathrm{H} 3 \mathrm{~K} 9 \mathrm{me} 2$ demethylation.

To understand the mechanism underlying this stimulation, Horton et al. determined the structure of PHF8 (residues 1$447)$ in complex with the H3K4me3K9me2 peptide and an unreactive analogue of $2-\mathrm{OG}, \mathrm{N}$-oxalylglycine (NOG), to $2.2 \AA$ resolution (Figure $3 \mathrm{~A}$ ). ${ }^{[19 \mathrm{a}]}$ The structure reveals that the K4me3 is recognized by binding in an aromatic cage in the $\mathrm{N}$-terminal PHD domain of the enzyme (Figure $3 \mathrm{C}$ ), which facilitates docking of the K9me2 substrate within the active site of the JmjC domain. The histone H3 peptide adopts an L-shaped conformation with an approximate right angle at K9. The PHD and JmjC domains of PHF8 interact with the substrate through an 
A)

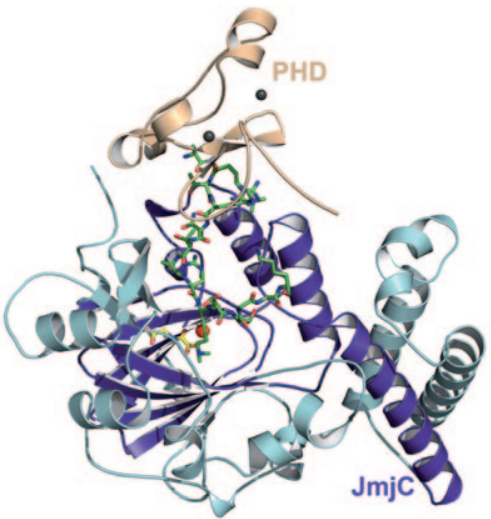

C)

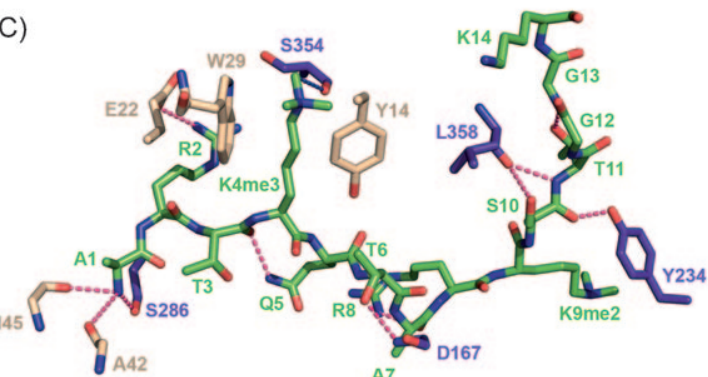

Figure 3. Molecular basis of H3K4me3 and H3K9me2 recognition by PHF8, A) Crystal structure of PHF8 (1-447) illustrating the PHD (light brown) and the JmjC domains (purple) in complex with the H3K4me3K9me2 peptide (green carbons), NOG (yellow carbons), Fe" (red sphere), and Zn" (gray sphere; PDB ID: 3KV4). The regions of the catalytic domain that do not correspond to the PHD and JmjC domains are denoted in cyan. B) Crystal structure of the catalytic domain of JMJD2A depicting the JmjN domain (red), JmjC domain (pink), H3K9me3 peptide (green carbons), NOG (yellow carbons) and Ni" (cyan; PDB ID: 20Q6). The remaining regions of the catalytic domain are shown in gray. C) Recognition of the H3K4me3K9me2 peptide by PHF8. Residues in the enzyme that engage in hydrogen bonds with the $\mathrm{H} 3$ peptide or form the aromatic cage that binds $\mathrm{K} 4 \mathrm{me} 3$ are illustrated. The color scheme is the same as in (A) with hydrogen bonds depicted in pink. D) The active site of PHF8 illustrating the H3K9me2 substrate, NOG, and residues from the enzyme that coordinate Fe" and K9me2. Colors are the same as in (A). Conventional and $\mathrm{CH}$... O hydrogen bonds are denoted in pink and blue, respectively, whereas the Fe" coordination is shown in black.

array of van der Waals contacts and hydrogen bonds with the main chain atoms of the $\mathrm{H} 3$ peptide (Figure $3 \mathrm{C}$ ). In addition, there are extensive interactions between the enzyme and the side chains of residues $\mathrm{A} 1-\mathrm{T} 11$ in the $\mathrm{H} 3$ peptide that confer specificity for K9me2. This binding mode is distinct from those observed in structures of human JMJD2A in complex with H3K9me3 and H3K36me3 peptides, in which the substrates adopt a more extended binding mode with few side-chain interactions within the substrate binding cleft of the enzyme (Figure 3B). ${ }^{[59]}$

An inspection of the active site of PHF8 explains its specificity for mono- and dimethyllysines. The dimethyl $\varepsilon$-amine group of K9me2 fits snugly in a pocket adjacent to the Fe" center and the substrate analogue NOG (Figure 3D). One methyl group of K9me2 faces toward the aromatic ring of $\mathrm{Y} 234$, whereas the other methyl group participates in $\mathrm{CH}$... O hydrogen bonds with the carboxylate group of D249 and amide group of N333. These unusual hydrogen bonds have also been implicated in trimethyllysine coordination in the active site of JMJD2A. ${ }^{[59 a]}$ Finally, the structure illustrates that the dimensions of the active site are too constrained to accommodate a trime- thyllysine due to a potential steric clash with NOG, thus providing a rationale for the monoand dimethyllysine specificity of PHF8.

An interesting facet of the PHF8 structure is the role that the linker region between the PHD and JmjC domains plays in defining substrate specificity. Although disordered in the PHF8 structure, the relatively short length of the linker forces the PHD and JmjC domains into close juxtaposition, thus optimizing the spatial recognition of K4me3 and K9me2 by the respective domains ${ }^{[19 a]}$ (Figure $3 \mathrm{~A}$ ). Conversely, biochemical characterization of the related human homologue KIAA1718 demonstrated that it demethylated H3K9me2 and H3K27me2 peptides lacking K4me3. However, the presence of $\mathrm{K} 4 \mathrm{me} 3$ in these substrates virtually abolished K9me2 demethylation but stimulated activity toward K27me2 approximately twofold. This unexpected finding is explained by the structure of KIAA1718, which was revealed to have a longer linker region that positions the PHD and JmjC domains distal to each other in relation to PHF8.

The distance between the aromatic cage in the PHD domain and the active site in the JmjC domain in KIAA1718 (37 $\AA$ ) is over twice the distance observed in the PHF8 complex with the H3K4me3K9me2 peptide. This distance is suited to the binding of the H3K4me3K27me2 peptide by the PHD and JmjC domains of KIAA1718 but is too long to accommodate $\mathrm{K} 4 \mathrm{me} 3$ and $\mathrm{K} 9 \mathrm{me} 2$ recognition within the context of the same peptide sequence. This concept was further tested by Horton et al. ${ }^{[19 a]}$ using chimeric enzymes in which the linker regions were swapped between PHF8 and KIAA1718. These chimeras displayed comparable activity toward the H3K4me3K9me2 peptide as well as H3K9me2 substrate, consistent with the predicted function of the linker in defining methylation site specificity.

Following the initial structural studies on PHF8, crystal structures of ceKDM7a in complex with various histone H3 peptides, including doubly methylated H3K4me3K9me2 and H3K4me3K27me2 peptides were determined. ${ }^{[57 c]}$ Surprisingly, these structures reveal a trans binding mode in which the enzyme associates with two separate histone $\mathrm{H} 3$ peptides. The K4me3 residue in one $\mathrm{H} 3$ peptide associates with the PHD domain of ceKDM7a, whereas the $\mathrm{K} 9 \mathrm{me} 2$ or $\mathrm{K} 27 \mathrm{me} 3$ residue in 
the second $\mathrm{H} 3$ peptides binds within the active site of the enzyme. This binding mode is distinct from that of PHF8, which displays a cis binding mode in which the $\mathrm{K} 4 \mathrm{me} 3$ and K9me2 from a single histone $\mathrm{H} 3$ peptide interact with the PHD and JmjC domains, respectively. Nonetheless, these findings with ceKDM7a, coupled with the recent reports that PHF8 also demethylates $\mathrm{H} 4 \mathrm{~K} 20 \mathrm{me} 1,{ }^{[52]}$ illustrate that these KDMs possess broad specificity in demethylating histone substrates.

\section{Summary}

Structural and functional studies of G9A and GLP as well as PHF8 have provided a framework for understanding the enzymatic mechanisms that dynamically regulate the methylation status of H3K9. G9A and GLP achieve specificity for H3K9 through selective recognition of the residues flanking $\mathrm{K} 9$ in the histone H3 N-terminal tail. ${ }^{[37 e]}$ This specificity permits these KMTs to distinguish between this site and the other major sites of lysine methylation in histones $\mathrm{H} 3$ and $\mathrm{H} 4$. Post-translational modifications of residues proximal to $\mathrm{K} 9$ in histone $\mathrm{H} 3$, including R8me, S10ph, and T11ph, abrogate methylation by G9A, whereas modifications that are distal to K9, such as K4me, have little or no effect on the specificity of these KMTs. ${ }^{[40-41]}$ In contrast, efficient demethylation of $\mathrm{H} 3 \mathrm{~K} 9 \mathrm{me} 1 / 2$ by PHF8 requires the association of $\mathrm{H} 3 \mathrm{~K} 4 \mathrm{me} 3$ with its $\mathrm{PHD}$ domain, facilitating $\mathrm{H} 3 \mathrm{~K} 9 \mathrm{me} 1 / 2$ demethylation via a cis binding mode in which both methyl marks are recognized within same $\mathrm{N}$-terminal tail of histone H3. ${ }^{[19 a]}$ In the absence of K4me3, PHF8 displays promiscuity in demethylating multiple methyllysine residues, including $\mathrm{H} 3 \mathrm{~K} 9, \mathrm{H} 3 \mathrm{~K} 27$, and $\mathrm{H} 3 \mathrm{~K} 36$ as well as H4K20. ${ }^{[19 b, 52]}$ In comparing the specificities of these enzymes, it is worth noting that G9A and GLP also possess methyllysine binding modules, specifically their ankyrin repeat domains that selectively bind to H3K9me1/2. ${ }^{[60]}$ Unlike the PHD domain in PHF8, the ankyrin domains of G9A and GLP have been proposed to promote the spreading of H3K9 methylation via a trans mechanism in which these enzymes are recruited to chromatin through interactions between their ankyrin domains and existing $\mathrm{H} 3 \mathrm{~K} 9 \mathrm{me} 1 / 2$ to direct the methylation of unmodified H3K9 in adjacent nucleosomes. In conclusion, these findings illustrate distinct mechanisms by which the methyllysine binding domains of G9A, GLP, and PHF8 target these enzymes to chromatin substrates.

\section{Outlook}

Structural and functional studies of the PHF8 family of KDMs have provided important new insights into its biological functions in gene regulation and how inactivating point mutations in PHF8 contribute to XLMR. Although the crystal structure of PHF8 illustrates the mechanism by which H3K4me3 binding by its PHD domain stimulates the demethylation of $\mathrm{H} 3 \mathrm{~K} 9 \mathrm{me} 1 / 2$, the recent finding that this KDM can also demethylate nucleosomal H4K20me1 indicates that its specificity determinants are more complex than initially thought. ${ }^{[52]}$ It is conceivable that the catalytic domain of PHF8 recognizes features in the nucleosome surface surrounding $\mathrm{H} 4 \mathrm{~K} 2 \mathrm{O}$ that do not require H3K4me3 association with the PHD domain of the enzyme to stimulate demethylation. Additional structural and biochemical studies are needed to fully understand its specificity in the context of nucleosomal substrates. In addition, the mechanism by which PHF8 mutations lead to XLMR remains unclear, particularly given its diverse functions in rRNA biosynthesis, cell-cycle control, and neuronal gene regulation. ${ }^{[51 a, 54-56]}$ It is likely that the multifaceted functions of PHF8 are collectively responsible for promoting proper neuronal differentiation, thus explaining how inactivating point mutations result in neurological defects and XLMR. Ongoing work on this KDM should continue to shed light on its biological functions in neuronal development as well as in other cell lineages.

Small-molecule inhibitors, such as BIX-01294, UNC0224, and their derivatives, have emerged as important tools for probing the functions of KMTs in vivo. ${ }^{[37 a-d, 46]}$ These compounds represent nascent steps toward the structure-based design of drugs that target the KMTs implicated in cancer and other diseases, analogous to the development and application of protein kinase inhibitors as new classes of drugs. Such strategies are also being applied to devise inhibitors of the LSD1 and JmjC classes of KDMs. ${ }^{[38 b]}$ With respect to the latter enzymes, several groups have recently reported small-molecule inhibitors of JmjC KDMs that are based on 2-OG analogues that possess pendant groups that enhance their binding affinity for JmjC KDMs and might offer a strategy for designing more specific inhibitors that are selective for distinct KDMs. ${ }^{[61]}$ Ultimately, these efforts will enable us to translate our knowledge of the structures, specificities, and mechanisms of KMTs and KDMs into the development of promising new therapeutics aimed at treating cancer and other epigenetic diseases linked to the aberrant functions of these enzymes.

\section{Acknowledgements}

We wish to thank Daniel Bochar for reading the review and providing insightful comments. S.H. was supported by an NIH Training Grant in Molecular Biophysics (T32-GM008270). The laboratory of R.T. is supported by NIH grant GM-073839.

Keywords: chromatin · demethylases $\cdot$ histone $\cdot$ methylation transcription $\cdot$ transferases

[1] K. Luger, J. C. Hansen, Curr. Opin. Struct. Biol. 2005, 15, 188-196.

[2] T. Kouzarides, Cell 2007, 128, 693-705.

[3] S. R. Bhaumik, E. Smith, A. Shilatifard, Nat. Struct. Mol. Biol. 2007, 14, $1008-1016$.

[4] S. L. Berger, Nature 2007, 447, 407-412.

[5] S. D. Taverna, H. Li, A. J. Ruthenburg, C. D. Allis, D. J. Patel, Nat. Struct. Mol. Biol. 2007, 14, 1025-1040.

[6] a) B. A. Boggs, P. Cheung, E. Heard, D. L. Spector, A. C. Chinault, C. D. Allis, Nat. Genet. 2002, 30, 73-76; b) M. D. Litt, M. Simpson, M. Gaszner, C. D. Allis, G. Felsenfeld, Science 2001, 293, 2453-2455; c) C. Maison, D. Bailly, A. H. Peters, J. P. Quivy, D. Roche, A. Taddei, M. Lachner, T. Jenuwein, G. Almouzni, Nat. Genet. 2002, 30, 329-334; d) J. E. Mermoud, B. Popova, A. H. Peters, T. Jenuwein, N. Brockdorff, Curr. Biol. 2002, 12, 247-251; e) K. Noma, C. D. Allis, S. I. Grewal, Science 2001, 293, $1150-$ 1155 ; f) A. H. Peters, J. E. Mermoud, D. O'Carroll, M. Pagani, D. Schweizer, N. Brockdorff, T. Jenuwein, Nat. Genet. 2002, 30, 77-80; g) C. Rou- 
geulle, J. Chaumeil, K. Sarma, C. D. Allis, D. Reinberg, P. Avner, E. Heard Mol. Cell. Biol. 2004, 24, 5475-5484.

[7] A. Barski, S. Cuddapah, K. Cui, T. Y. Roh, D. E. Schones, Z. Wang, G. Wei, I. Chepelev, K. Zhao, Cell 2007, 129, 823-837.

[8] a) I. Okamoto, A. P. Otte, C. D. Allis, D. Reinberg, E. Heard, Science 2004 303, 644-649; b) J. Silva, W. Mak, I. Zvetkova, R. Appanah, T. B. Nesterova, Z. Webster, A. H. Peters, T. Jenuwein, A. P. Otte, N. Brockdorff, Dev. Cell 2003, 4, $481-495$.

[9] a) A. H. Peters, S. Kubicek, K. Mechtler, R. J. O'Sullivan, A. A. Derijck, L. Perez-Burgos, A. Kohlmaier, S. Opravil, M. Tachibana, Y. Shinkai, J. H. Martens, T. Jenuwein, Mol. Cell 2003, 12, 1577-1589; b) J. C. Rice, S. D. Briggs, B. Ueberheide, C. M. Barber, J. Shabanowitz, D. F. Hunt, Y. Shinkai, C. D. Allis, Mol. Cell 2003, 12, 1591-1598; c) G. Schotta, M. Lachner, K. Sarma, A. Ebert, R. Sengupta, G. Reuter, D. Reinberg, T. Jenuwein, Genes Dev. 2004, 18, 1251-1262.

[10] X. Cheng, R. M. Blumenthal, Biochemistry 2010, 49, 2999-3008.

[11] a) S. C. Dillon, X. Zhang, R. C. Trievel, X. Cheng, Adv. Genome Biol. 2005 , 6, 227; b) C. Qian, M. M. Zhou, Cell. Mol. Life Sci. 2006, 63, 2755-2763.

[12] M. Tachibana, K. Sugimoto, T. Fukushima, Y. Shinkai, J. Biol. Chem. 2001, 276, 25309-25317.

[13] H. Ogawa, K. Ishiguro, S. Gaubatz, D. M. Livingston, Y. Nakatani, Science 2002, 296, 1132-1136

[14] a) D. C. Schultz, K. Ayyanathan, D. Negorev, G. G. Maul, F. J. Rauscher III, Genes Dev. 2002, 16, 919-932; b) L. Yang, L. Xia, D. Y. Wu, H. Wang H. A. Chansky, W. H. Schubach, D. D. Hickstein, Y. Zhang, Oncogene 2002, 21, 148-152.

[15] K. C. Kim, L. Geng, S. Huang, Cancer Res. 2003, 63, 7619-7623.

[16] a) D. O'Carroll, H. Scherthan, A. H. Peters, S. Opravil, A. R. Haynes, G. Laible, S. Rea, M. Schmid, A. Lebersorger, M. Jerratsch, L. Sattler, M. G. Mattei, P. Denny, S. D. Brown, D. Schweizer, T. Jenuwein, Mol. Cell. Biol. 2000, 20, 9423-9433; b) S. Rea, F. Eisenhaber, D. O'Carroll, B. D. Strahl, Z. W. Sun, M. Schmid, S. Opravil, K. Mechtler, C. P. Ponting, C. D. Allis, T. Jenuwein, Nature 2000, 406, 593-599.

[17] K. Yamane, C. Toumazou, Y. Tsukada, H. Erdjument-Bromage, P. Tempst, J. Wong, Y. Zhang, Cell 2006, 125, 483-495

[18] a) P. A. Cloos, J. Christensen, K. Agger, A. Maiolica, J. Rappsilber, T. Antal K. H. Hansen, K. Helin, Nature 2006, 442, 307-311; b) B. D. Fodor, S. Kubicek, M. Yonezawa, R. J. O'Sullivan, R. Sengupta, L. Perez-Burgos, S. Opravil, K. Mechtler, G. Schotta, T. Jenuwein, Genes Dev. 2006, 20, 1557 1562; c) R. J. Klose, K. Yamane, Y. Bae, D. Zhang, H. Erdjument-Bromage, P. Tempst, J. Wong, Y. Zhang, Nature 2006, 442, 312-316; d) J. R. Whetstine, A. Nottke, F. Lan, M. Huarte, S. Smolikov, Z. Chen, E. Spooner, E. Li, G. Zhang, M. Colaiacovo, Y. Shi, Cell 2006, 125, 467-481.

[19] a) J. R. Horton, A. K. Upadhyay, H. H. Qi, X. Zhang, Y. Shi, X. Cheng, Nat Struct. Mol. Biol. 2010, 17, 38-43; b) C. Loenarz, W. Ge, M. L. Coleman N. R. Rose, C. D. Cooper, R. J. Klose, P. J. Ratcliffe, C. J. Schofield, Hum Mol. Genet. 2010, 19, 217-222

[20] R. Schneider, A. J. Bannister, T. Kouzarides, Trends Biochem. Sci. 2002, 27 $396-402$

[21] The UniProt Consortium, Nucleic Acids Res. 2010, 38, D142-D148.

[22] M. Tachibana, J. Ueda, M. Fukuda, N. Takeda, T. Ohta, H. Iwanari, T. Sakihama, T. Kodama, T. Hamakubo, Y. Shinkai, Gene Devel. 2005, 19, 815826.

[23] N. Feldman, A. Gerson, J. Fang, E. Li, Y. Zhang, Y. Shinkai, H. Cedar, Y. Bergman, Nat. Cell Biol. 2006, 8, 188-U155.

[24] D. K. Ma, C. H. J. Chiang, K. Ponnusamy, G. L. Ming, H. J. Song, Stem Cells 2008, 26, 2131-2141.

[25] S. Epsztejn-Litman, N. Feldman, M. Abu-Remaileh, Y. Shufaro, A. Gerson, J. Ueda, R. Deplus, F. Fuks, Y. Shinkai, H. Cedar, Y. Bergman, Nat. Struct Mol. Biol. 2008, 15, 1176-1183.

[26] Z. H. Xin, M. Tachibana, M. Guggiari, E. Heard, Y. Shinkai, J. Wagstaff, J. Biol. Chem. 2003, 278, 14996-15000.

[27] a) Y. Kondo, L. Shen, S. Ahmed, Y. Boumber, Y. Sekido, B. R. Haddad, J. P. Issa, Plos One 2008, 3, e2037; b) Y. Kondo, L. Shen, S. Suzuki, T. Kurokawa, K. Masuko, Y. Tanaka, H. Kato, Y. Mizuno, M. Yokoe, F. Sugauchi, N. Hirashima, E. Orito, H. Osada, R. Ueda, Y. Guo, X. Chen, J. P. Issa, Y. Sekido, Hepatol. Res. 2007, 37, 974-983.

[28] R. J. Wozniak, W. T. Klimecki, S. S. Lau, Y. Feinstein, B. W. Futscher, Oncogene 2007, 26, 77-90.

[29] J. Huang, J. Dorsey, S. Chuikov, X. Y. Zhang, T. Jenuwein, D. Reinberg, S. L. Berger, J. Biol. Chem. 2010, 285, 9636-9641.
[30] J. F. Couture, R. C. Trievel, Curr. Opin. Struct. Biol. 2006, 16, $753-760$.

[31] W. R. Taylor, B. Xiao, S. J. Gamblin, K. Lin, Comput. Biol. Chem. 2003, 27, $11-15$

[32] a) R. C. Trievel, E. M. Flynn, R. L. Houtz, J. H. Hurley, Nat. Struct. Biol. 2003, 10, 545-552; b) B. Xiao, C. Jing, J. R. Wilson, P. A. Walker, N. Vasisht, G. Kelly, S. Howell, I. A. Taylor, G. M. Blackburn, S. J. Gamblin Nature 2003, 421, 652-656; c) X. Zhang, Z. Yang, S. I. Khan, J. R. Horton, H. Tamaru, E. U. Selker, X. Cheng, Mol. Cell 2003, 12, 177-185.

[33] a) S. Chuikov, J. K. Kurash, J. R. Wilson, B. Xiao, N. Justin, G. S. Ivanov, K. McKinney, P. Tempst, C. Prives, S. J. Gamblin, N. A. Barlev, D. Reinberg, Nature 2004, 432, 353-360; b) J. F. Couture, E. Collazo, G. Hauk, R. C. Trievel, Nat. Struct. Mol. Biol. 2006, 13, 140-146; c) K. Subramanian, D. Jia, P. Kapoor-Vazirani, D. R. Powell, R. E. Collins, D. Sharma, J. Peng, X Cheng, P. M. Vertino, Mol. Cell 2008, 30, 336-347.

[34] a) J. F. Couture, E. Collazo, J. S. Brunzelle, R. C. Trievel, Genes Dev. 2005, 19, 1455-1465; b) B. Xiao, C. Jing, G. Kelly, P. A. Walker, F. W. Muskett, T. A. Frenkiel, S. R. Martin, K. Sarma, D. Reinberg, S. J. Gamblin, J. R. Wilson, Genes Dev. 2005, 19, 1444-1454.

[35] S. M. Southall, P. S. Wong, Z. Odho, S. M. Roe, J. R. Wilson, Mol. Cell 2009, 33, $181-191$

[36] C. Qian, X. Wang, K. Manzur, Sachchidanand, A. Farooq, L. Zeng, R. Wang, M. M. Zhou, J. Mol. Biol. 2006, 359, 86-96.

[37] a) Y. Chang, T. Ganesh, J. R. Horton, A. Spannhoff, J. Liu, A. Sun, X Zhang, M. T. Bedford, Y. Shinkai, J. P. Snyder, X. Cheng, J. Mol. Biol. 2010 400, 1-7; b) Y. Chang, X. Zhang, J. R. Horton, A. K. Upadhyay, A. Spannhoff, J. Liu, J. P. Snyder, M. T. Bedford, X. Cheng, Nat. Struct. Mol. Biol. 2009, 16, 312-317; c) F. Liu, X. Chen, A. Allali-Hassani, A. M. Quinn, G. A Wasney, A. P. Dong, D. Barsyte, I. Kozieradzki, G. Senisterra, I. Chau, A. Siarheyeva, D. B. Kireev, A. Jadhav, J. M. Herold, S. V. Frye, C. H. Arrowsmith, P. J. Brown, A. Simeonov, M. Vedadi, J. Jin, J. Med. Chem. 2009, 52, 7950-7953; d) F. Liu, X. Chen, A. Allali-Hassani, A. M. Quinn, T. J. Wigle, G. A. Wasney, A. P. Dong, G. Senisterra, I. Chau, A. Siarheyeva, J. L. Norris, D. B. Kireev, A. Jadhav, J. M. Herold, W. P. Janzen, C. H. Arrowsmith, S. V. Frye, P. J. Brown, A. Simeonov, M. Vedadi, J. A. Jin, J. Med. Chem. 2010, 53, 5844-5857; e) H. Wu, J. R. Min, V. V. Lunin, T. Antoshenko, L. Dombrovski, H. Zeng, A. Allali-Hassani, V. Campagna-Slater, M. Vedadi, C. H. Arrowsmith, A. N. Plotnikov, M. Schapira, Plos One 2010, 5.

[38] a) R. A. Copeland, M. E. Solomon, V. M. Richon, Nat. Rev. Drug Discovery 2009, 8, 724-732; b) A. Spannhoff, A. T. Hauser, R. Heinke, W. Sippl, M. Jung, ChemMedChem 2009, 4, 1568-1582.

[39] P. Rathert, X. Zhang, C. Freund, X. D. Cheng, A. Jeltsch, Chem. Biol. 2008, $15,5-11$

[40] P. Rathert, A. Dhayalan, M. Murakami, X. Zhang, R. Tamas, R. Jurkowska, Y. Komatsu, Y. Shinkai, X. D. Cheng, A. Jeltsch, Nat. Chem. Biol. 2008, 4 344-346.

[41] H. G. Chin, M. Pradhan, P. O. Esteve, D. Patnaik, T. C. Evans, Jr., S. Pradhan, Biochemistry 2005, 44, 12998-13006.

[42] S. Pal, S. N. Vishwanath, H. Erdjument-Bromage, P. Tempst, S. Sif, Mol Cell. Biol. 2004, 24, 9630-9645.

[43] a) J. F. Couture, L. M. Dirk, J. S. Brunzelle, R. L. Houtz, R. C. Trievel, Proc. Natl. Acad. Sci. USA 2008, 105, 20659-20664; b) J. F. Couture, G. Hauk M. J. Thompson, G. M. Blackburn, R. C. Trievel, J. Biol. Chem. 2006, 281, $19280-19287$; c) P. A. Del Rizzo， J. F. Couture， L. M. Dirk， B. S. Strunk M. S. Roiko, J. S. Brunzelle, R. L. Houtz, R. C. Trievel, J. Biol. Chem. 2010, 285, 31849-3158.

[44] a) H. G. Chin, D. Patnaik, P. O. Esteve, S. E. Jacobsen, S. Pradhan, Biochemistry 2006, 45, 3272-3284; b) P. O. Esteve, D. Patnaik, H. G. Chin, J. Benner, M. A. Teitell, S. Pradhan, Nucleic Acids Res. 2005, 33, 3211-3223.

[45] D. Greiner, T. Bonaldi, R. Eskeland, E. Roemer, A. Imhof, Nat. Chem. Biol. 2005, 1, 143-145

[46] S. Kubicek, R. J. O'Sullivan, E. M. August, E. R. Hickey, Q. Zhan, M. L. Teodoro, S. Rea, K. Mechtler, J. A. Kowalski, C. A. Homon, T. A. Kelly, T. Jenuwein, Mol. Cell 2007, 25, 473-481.

[47] Y. Shi, C. Desponts, J. T. Do, H. S. Hahm, H. R. Scholer, S. Ding, Cell. Stem Cell 2008, 3, 568-574.

[48] a) J. A. Simon, C. A. Lange, Mutat. Res. 2008, 647, 21-29; b) S. Varambally, S. M. Dhanasekaran, M. Zhou, T. R. Barrette, C. Kumar-Sinha, M. G. Sanda, D. Ghosh, K. J. Pienta, R. G. A. B. Sewalt, A. P. Otte, M. A. Rubin A. M. Chinnaiyan, Nature 2002, 419, 624-629.

[49] a) R. Hamamoto, Y. Furukawa, M. Morita, Y. limura, F. P. Silva, M. Li, R. Yagyu, Y. Nakamura, Nat. Cell Biol. 2004, 6, 731-740; b) R. Hamamoto, 
F. P. Silva, M. Tsuge, T. Nishidate, T. Katagiri, Y. Nakamura, Y. Furukawa, Cancer Sci. 2006, 97, 113-118.

[50] R. J. Klose, E. M. Kallin, Y. Zhang, Nat. Rev. Genet. 2006, 7, 715-727.

[51] a) D. Kleine-Kohlbrecher, J. Christensen, J. Vandamme, I. Abarrategui, M. Bak, N. Tommerup, X. Shi, O. Gozani, J. Rappsilber, A. E. Salcini, K. Helin, Mol. Cell 2010, 38, 165-178; b) Y. Tsukada, T. Ishitani, K. I. Nakayama, Genes Dev. 2010, 24, 432-437.

[52] a) W. Liu, B. Tanasa, O. V. Tyurina, T. Y. Zhou, R. Gassmann, W. T. Liu, K. A. Ohgi, C. Benner, I. Garcia-Bassets, A. K. Aggarwal, A. Desai, P. C. Dorrestein, C. K. Glass, M. G. Rosenfeld, Nature 2010, 466, 508-512; b) H. H. Qi, M. Sarkissian, G. Q. Hu, Z. Wang, A. Bhattacharjee, D. B. Gordon, M. Gonzales, F. Lan, P. P. Ongusaha, M. Huarte, N. K. Yaghi, H. Lim, B. A. Garcia, L. Brizuela, K. Zhao, T. M. Roberts, Y. Shi, Nature 2010, 466, 503-507.

[53] a) F. E. Abidi, M. G. Miano, J. C. Murray, C. E. Schwartz, Clin. Genet. 2007 72, 19-22; b) A. M. Koivisto, S. Ala-Mello, S. Lemmela, H. A. Komu, J. Rautio, I. Jarvela, Clin. Genet. 2007, 72, 145-149; c) F. Laumonnier, S. Holbert, N. Ronce, F. Faravelli, S. Lenzner, C. E. Schwartz, J. Lespinasse, H. Van Esch, D. Lacombe, C. Goizet, F. Phan-Dinh Tuy, H. van Bokhoven, J. P. Fryns, J. Chelly, H. H. Ropers, C. Moraine, B. C. Hamel, S. Briault, J. Med. Genet. 2005, 42, 780-786.

[54] J. Qiu, G. Shi, Y. Jia, J. Li, M. Wu, S. Dong, J. Wong, Cell. Res. 2010, 20, 908-918.

[55] a) W. Feng, M. Yonezawa, J. Ye, T. Jenuwein, I. Grummt, Nat. Struct. Mol. Biol. 2010, 17, 445-450; b) Z. Zhu, Y. Wang, X. Li, L. Xu, X. Wang, T. Sun, X. Dong, L. Chen, H. Mao, Y. Yu, J. Li, P. A. Chen, C. D. Chen, Cell Res. 2010, 20, 794-801.

[56] K. Fortschegger, P. de Graaf, N. S. Outchkourov, F. M. van Schaik, H. T. Timmers, R. Shiekhattar, Mol. Cell. Biol. 2010, 30, 3286-3298.

[57] a) L. Yu, Y. Wang, S. Huang, J. Wang, Z. Deng, Q. Zhang, W. Wu, X. Zhang, Z. Liu, W. Gong, Z. Chen, Cell Res. 2010, 20, 166-173; b) W. W.
Yue, V. Hozjan, W. Ge, C. Loenarz, C. D. Cooper, C. J. Schofield, K. L. Kavanagh, U. Oppermann, M. A. McDonough, FEBS Lett. 2010, 584, $825-$ 830 ; c) Y. Yang, L. Hu, P. Wang, H. Hou, Y. Lin, Y. Liu, Z. Li, R. Gong, X. Feng, L. Zhou, W. Zhang, Y. Dong, H. Yang, H. Lin, Y. Wang, C. D. Chen, Y. Xu, Cell Res. 2010, 20, 886-898.

[58] Z. Chen, J. Zang, J. Whetstine, X. Hong, F. Davrazou, T. G. Kutateladze, M. Simpson, Q. Mao, C. H. Pan, S. Dai, J. Hagman, K. Hansen, Y. Shi, G. Zhang, Cell 2006, 125, 691-702.

[59] a) J.-F. Couture, E. Collazo, P. A. Ortiz-Tello, J. S. Brunzelle, R. C. Trievel, Nat. Struct. Mol. Biol. 2007, 14, 689-695; b) S. S. Ng, K. L. Kavanagh, M. A. McDonough, D. Butler, E. S. Pilka, B. M. R. Lienard, J. E. Bray, P. Savitsky, O. Gileadi, F. von Delft, N. R. Rose, J. Offer, J. C. Scheinost, T. Borowski, M. Sundstrom, C. J. Schofield, U. Oppermann, Nature 2007, 448, 87-91; c) Z. Chen, J. Zang, J. Kappler, X. Hong, F. Crawford, Q. Wang, F. Lan, C. Jiang, J. Whetstine, S. Dai, K. Hansen, Y. Shi, G. Zhang, Proc. Natl. Acad. Sci. USA 2007, 104, 10818-10823.

[60] R. E. Collins, J. P. Northrop, J. R. Horton, D. Y. Lee, X. Zhang, M. R. Stallcup, X. Cheng, Nat. Struct. Mol. Biol. 2008, 15, 245-250.

[61] a) S. Hamada, T. D. Kim, T. Suzuki, Y. Itoh, H. Tsumoto, H. Nakagawa, R. Janknecht, N. Miyata, Bioorg. Med. Chem. Lett. 2009, 19, 2852-2855; b) S. Hamada, T. Suzuki, K. Mino, K. Koseki, F. Oehme, I. Flamme, H. Ozasa, Y. Itoh, D. Ogasawara, H. Komaarashi, A. Kato, H. Tsumoto, H. Nakagawa, M. Hasegawa, R. Sasaki, T. Mizukami, N. Miyata, J. Med. Chem 2010, 53, 5629-5638; c) N. R. Rose, E. C. Woon, G. L. Kingham, O. N King, J. Mecinovic, I. J. Clifton, S. S. Ng, J. Talib-Hardy, U. Oppermann, M. A. McDonough, C. J. Schofield, J. Med. Chem. 2010, 53, 1810-1818.

Received: September 14, 2010

Published online on January 5, 2011 